\title{
Intussusception associated with bacterial meningitis
}

\author{
E Crushell, O Flanagan, M Devins, K Dunne, J Gleeson
}

\begin{abstract}
Despite its common association with viral illnesses, intussusception has only rarely been found in the presence of bacterial infections. Two infants are described, both of whom were admitted to hospital with bilious vomiting, drowsiness, and dehydration. Both infants required urgent intravenous volume expansion. Intussusception was confirmed, and reduction was achieved by enema in both cases. Recovery was slow, and one infant developed a seizure. Evidence of meningococcal meningitis was found in both, with septicaemia in one. Neurological outcome is normal to date, and there has been no recurrence of intussusception in either case.

(Arch Dis Child 2001;85:56-57)
\end{abstract}

Keywords: intussusception; meningitis; sepsis

The presentation of intussusception in infancy can be misleading as it often mimics that of other diseases such as sepsis, meningitis, and encephalopathy. ${ }^{12}$ Fever and lethargy may be the only symptoms, and differentiation may require ultrasonography and a septic work up. Although intussusception is often found in association with minor viral illnesses, ${ }^{3}$ the association of bacterial meningitis and intussusception has not been reported previously. Here we describe two cases that presented within one week of each other to two different paediatric units in the West of Ireland.

Paediatrics, Sligo

General Hospital,

Ireland

E Crushell

J Gleeson

Department of Paediatrics, University College Hospital, Galway, Ireland

O Flanagan

$M$ Devins

K Dunne

Correspondence to: Dr Crushell, Department of Paediatrics, UCD, Children's Research Centre, Our Lady's Hospital for Sick Children, Crumlin, Dublin 12, Ireland ellen.crushell@ucd.ie

Accepted 21 February 2001 there was a mass palpable in the right upper quadrant.

Laboratory tests showed haemoglobin 106 g/l, white blood cell count 19.6 (neutrophils 15.1) $\times 10^{9} / 1$, and platelets $271 \times 10^{9} / 1$. Abdominal radiographs suggested intussusception with a paucity of gas in the right hemiabdomen. Abdominal ultrasonography showed an ileocolic intussusception with a positive "target sign". The intussusception was reduced with an air enema. Although the vomiting ceased, there was no real improvement in his clinical condition; therefore it was decided to perform a lumbar puncture. Examination of cerebrospinal fluid (CSF) 48 hours after admission showed a white blood cell count of $992 / \mathrm{mm}^{3}$ ( $85 \%$ polymorphs) in the presence of 8 red blood cells $/ \mathrm{mm}^{3}$, protein $0.7 \mathrm{~g} / \mathrm{l}$, and glucose $2 \mathrm{mmol} / 1$. No organisms were detected. Blood, urine, and CSF cultures were sterile. Meningococcal DNA was identified in serum by polymerase chain reaction. He was treated with a 10 day course of cefotaxime. Neurological follow up has been normal.

Case 2

A 7 month old girl was brought to hospital with lethargy and vomiting. She had been unwell for one week with intermittent fevers and lethargy. On the morning of admission she had persistent vomiting, initially of undigested food, later becoming bilious. On examination she was sleepy and appeared very unwell, with pallor and mottling of the skin. Capillary refill time was more than six seconds. Temperature was $38^{\circ} \mathrm{C}$, and heart rate was 130 beats/min. There was a sausage shaped mass palpable in the right upper abdominal quadrant and the rectum was empty. There were no rashes, but the fontanelle was noted to feel full. The infant was treated with intravenous volume expansion $(0.9 \%$ saline), and intravenous cefotaxime was begun. Barium enema confirmed an ileocolic intussusception which was reduced hydrostatically. After the procedure, there was little clinical change. She developed a generalised tonic clonic seizure which responded to diazepam.

Laboratory investigations showed haemoglobin $102 \mathrm{~g} / 1$, white blood cell count 18.5 (neutrophils 14.6 ) $\times 10^{9} / 1$, platelets $641 \times 10^{9} / 1$, glucose $9 \mathrm{mmol} / \mathrm{l}$, and electrolytes normal. CSF examination showed white blood cells $16250 / \mathrm{mm}^{3}$ (95\% polymorphs), red blood 
cells $20 / \mathrm{mm}^{3}$, protein $2 \mathrm{~g} / 1$, and glucose 4.1 $\mathrm{mmol} / \mathrm{l}$. There were Gram negative diplococci present on microscopy. Blood, urine, and CSF cultures were sterile. Serum polymerase chain reaction for meningococcal DNA was inconclusive. She gradually improved and received a seven day course of intravenous penicillin. Neurological examination on discharge was normal.

\section{Discussion}

This is the first report of intussusception occurring with bacterial meningitis. Intussusception is the commonest cause of bowel obstruction in infancy and early childhood; the reported incidence varies from 0.5 to 4 per 1000 live births. In 1999, the Irish national incidence of meningococcal disease was 14.75 per 100000 while the incidence in the West of Ireland was eight per $100000{ }^{4}$ The probability of both illnesses occurring together is in the order of 1 in 20 million.

Intussusception may present like meningococcal disease and vice versa. ${ }^{12}$ A palpable abdominal mass is highly suggestive of intussusception; however it is found in only $63 \%$ of cases. ${ }^{5}$ In our experience, a sick lethargic infant is usually initially treated with broad spectrum antibiotics until an intussusception is diagnosed and reduced and the infant improves. Spontaneous reduction of an intussusception may occur in a small percentage of cases. ${ }^{6}$ However, for the most part, intervention using hydrostatic or pneumatic pressure (and occasionally surgery) is required.

It is notable that in our two patients, despite successful reduction of the intussusception, the overall clinical picture showed no improvement, with persisting poor perfusion and lethargy. Patient 1 had meningococcal meningitis with septicaemia (petechiae and serum positive for meningococcal DNA), whereas patient 2 had meningitis, probably meningococcal, without evidence of septicaemia.

The relation between intussusception and infection is not clear. Viral infections are commonly associated with intussusception. ${ }^{3}$ The seasonal peaks in the incidence of intussusception in spring and autumn coincide with the seasonality of adenovirus infection. Rotavirus has been associated with intussusception, and reports of intussusception following administration of rotavirus vaccine led to its withdrawal in $1999 .^{7}$ Although there is a report of intussusception in the presence of aseptic meningitis caused by human herpes virus $6,{ }^{8}$ an association with bacterial meningitis has not been documented previously. Some enteric bacterial pathogens, including Escherichia coli 0157:H7, Yersinia, and Salmonella species, have rarely been implicated in the causation of intussusception..$^{9} 10$

Local factors are probably the cause of intussusception in the presence of an enteropathogenic organism. It has been postulated that hypertrophied Peyer's patches and oedematous mucosa associated with viral infections may serve as a lead point for an intussusception. Identifiable lead points, though, are unusual in early childhood intussusception, occurring in only $4 \%$ of those under the age of 2 years. ${ }^{11}$ The cause of intussusception accompanying non-enteropathogenic bacterial infection such as meningococcal sepsis is more difficult to find. It may be related to altered gastrointestinal motility as a consequence of circulating inflammatory mediators. This theory is supported by recent animal studies in which intussusception was induced in mice following intraperitoneal injections of bacterial wall lipopolysaccharide. ${ }^{12}$

\section{CONCLUSION}

In general, the reduction of an uncomplicated intussusception would be expected to lead to a dramatic improvement in colour and humour. Failure to improve after reduction should prompt a search for coexisting bacterial infections such as meningitis, as found in these cases.

1 Goetting MG, Tiznado-Garcia E, Bakdash TF. Intussusception encephalopathy: an underrecognized cause of coma in children. Pediatr Neurol 1990;6:419-21.

2 Birkhahn R, Fiorini M, Gaeta TJ. Painless intussusception and altered mental status. Am f Emerg Med 1999;17:345-7.

3 Nicolas JC, Ingrand D, Fortier B, et al. A one-year virological survey of acute intussusception in childhood. 7 Med Virol 1982;9:267-71.

4 Irish National Disease Surveillance Centre. Report on the enhanced surveillance of bacterial meningitis including meningococcal septicaemia in the Rep. of Ireland. Analysis of quarterly returns to the Department of Health and Children 1997-1999. http://www ndsc.ie.

5 Stringer MD, Pablot SM, Brereton RJ. Paediatric intussusception. Br f Surg 1992;79:867-76.

6 Kornecki A, Daneman A, Navarro O, et al. Spontaneous Kornecki A, Daneman A, Navarro O, et al. Spontaneous
reduction of intussusception: clinical spectrum, managereduction of intussusception: clinical spectrum,

ment and outcome. Pediatr Radiol $2000 ; 30: 58-63$.
7 Intussusception among recipients of rotavirus vaccineIntussusception among recipients of rotavirus vaccine-
United States, 1998-1999. MMWR Morb Mortal Wkly Rep 1999;48:577-81

8 Koranyi KI, Chapman J, Scherzer D. Irritability and vomitng in a five-month old. Pediatr Infect Dis f 1997;16:11869.

9 Lopez EL, Devoto S, Woloj M, et al. Intussusception associated with Escherichia coli 0157:H7. Pediatr Infect Dis $\mathcal{f}$ 1989;8:471-3.

10 Koo JW, Cho CR, Cha SJ, et al. Intussusception associated with Yersinia pseudotuberculosis infection. Acta Paediatr 1996;85:1253-5.

11 Ong NT, Beasley SW. The leadpoint in intussusception. $f$ Pediatr Surg 1990;25:640-3.

12 Lin Z, Cohen P, Nissan A, et al. Bacterial wall lipopolysaccharide as a cause of intussusception in mice. $\mathcal{F}$ Pediatr Gastroenterol Nutr 1998;27:301-5. 